Article

\title{
Is There Coupling Effect between Financial Support and Improvement of Human Settlement? A Case Study of the Middle and Lower Regions of the Yangtze River, China
}

\author{
Weimin Yan ${ }^{1,2, *}$, Benhong Peng ${ }^{1,2}$, Guo Wei $^{3}$ and Anxia Wan ${ }^{2}$ \\ 1 Binjiang College, Nanjing University of Information Science and Technology, Wuxi 214105, China; \\ 002426@nuist.edu.cn \\ 2 School of Management Science and Engineering, Nanjing University of Information Science \& Technology, \\ Nanjing 210044, China; 002466@nuist.edu.cn \\ 3 Department of Mathematics and Computer Science, University of North Carolina at Pembroke, \\ Pembroke, NC 28372, USA; guo.wei@uncp.edu \\ * Correspondence: ywm@nuist.edu.cn; Tel.: +86-158-5290-8898
}

Citation: Yan, W.; Peng, B.; Wei, G.; Wan, A. Is There Coupling Effect between Financial Support and Improvement of Human Settlement? A Case Study of the Middle and Lower Regions of the Yangtze River, China. Sustainability 2021, 13, 8131. https://doi.org/10.3390/su13158131

Academic Editor: Anna Mazzi

Received: 30 May 2021

Accepted: 14 July 2021

Published: 21 July 2021

Publisher's Note: MDPI stays neutral with regard to jurisdictional claims in published maps and institutional affiliations.

Copyright: (c) 2021 by the authors. Licensee MDPI, Basel, Switzerland. This article is an open access article distributed under the terms and conditions of the Creative Commons Attribution (CC BY) license (https:// creativecommons.org/licenses/by/ $4.0 /)$.

\begin{abstract}
Currently, there are opposing views on the issue of whether financial support plays a role in improving the human settlement. This article is dedicated to exploring the mutual influence of financial support and the improvement of human settlements from the perspective of coupling effects, and determining the characteristics of coupling and coordination to promote the sustainable development of China and developing countries. This paper uses the entropy method and the coupling coordination model to estimate the coupling and coordination types of financial support and human settlements in seven provinces in the middle and lower reaches of the Yangtze River from 2005 to 2018. In addition, the spatial autocorrelation model is adopted to determine the spatial agglomeration characteristics of the coupling and coordination of financial support and human settlements. All in all, this paper believes that financial support has improved the human settlements, and that there is a coupling effect. Specifically, the coupling coordination value of financial support and human settlements fluctuated from 0.034 to 0.436 , showing an inverted U-shaped development trend as a whole. In addition, the correlation between financial support and the improvement of the human settlements is currently in the stage of barely balanced development, and there is a gap between benign and coordinated development. Secondly, the coupling and coordination between financial support and human settlements has significant spatial agglomeration characteristics, and the coupling effect in the eastern region is weaker than that in the western region. In particular, Jiangxi was mainly distributed as high to high agglomeration, and Jiangsu was mainly distributed as high to low agglomeration. It has formed a coupling and coordinated development area with Jiangsu-Jiangxi as the axis, radiating the development of adjacent areas. This research reveals the heterogeneity of financial support to the improvement of human settlements in different regions, portrays the coupling characteristics of financial support and the improvement of human settlements, and provides ideas for the coordinated development of the two.
\end{abstract}

Keywords: financial support; improvement of human settlement; coupling effect; middle and lower reaches of the Yangtze River

\section{Introduction}

Over the last few years, the world economy has continued to grow. In $2017,75 \%$ of the world's economies had accelerated their development, and by the beginning of 2018, the global economic growth rate reached $4.7 \%$; the global economic recovery tracking index also reached its peak [1]. However, the fast pace of development brings environmental problems, and about 8.3 million people die each year due to environmental pollution [2]. In poorer countries, it is mainly manifested in unsanitary water use and indoor air pollution. 
Since the reform and opening up in 1978, China has made great progress in economic development and environmental protection; however, at the same time, ecological problems such as land desertification, sandstorms, and smog have become increasingly prominent, gradually threatening the human settlement in China [3]. In the middle and lower regions of the Yangtze River, as one of China's main economic belts, soil erosion, resource depletion, and ecological damage have severely restricted regional economic development, and financial support that is compatible with human settlement is essential [4]. So, how to break through the current development path? How to create and achieve a higher level of human settlements through financial support? This has become an urgent problem for local governments in China to solve. Therefore, it is of great significance to study the coordinated development of financial support and the improvement of human settlements.

Specifically, it is necessary to study the coordination relationship between financial support and the improvement of the human settlements. Relevant scholars have proven that there is obvious regional heterogeneity between financial support and the improvement of human settlements [5], and some scholars have found that there is no regional difference between the two [6]. Obviously, there are different viewpoints in the coupling study of financial support and the improvement of human settlements. At the same time, there are still blank points in the quantitative research on coupling coordination, such as coupling trend and situation evolution. In addition, China is the world's largest developing country, and has the typical characteristics of a developing country. Therefore, studying the coupling characteristics of China's typical regional financial support and improvement of human settlements can provide guidance for developing countries to achieve regional sustainable development. For the first time, this article discusses the evolutionary trend of coupling between financial support and the improvement of human settlements in the middle and lower reaches of the Yangtze River in China from two dimensions of time and space. Finally, it provides suggestions for the government, financial institutions, and green enterprises to complete ecological construction. This has important theoretical and practical value.

\section{Literature Reviews}

Since the concept of human settlement science was coined by Greek scholar Doxiadis, the theory of human settlement has been continuously improved and the research on the evaluation of the quality of human settlement has followed suit. Some scholars have conducted research on the construction of human settlement indicators. Francescato (1991) [7] constructed a human settlement satisfaction evaluation model from the perspective of human settlement, which enriched the human settlement theory. William (2002) [8] analyzed the location choice of residents, and from the influencing factors of the human settlement, he built a human settlement evaluation system. Stidger (2003) [9] combined Francescarto and Reed's research ideas to build a neighborhood index system to evaluate city's livability and contribution to the urban human settlement evaluation. Some scholars have innovated research methods: Ge and Hokao (2004) [10] used the AHP method to build a human settlement index system and a comprehensive human settlement evaluation model, and studied the factors affecting the human settlement through a questionnaire survey, which fully reflected the human settlement level in Saga, Japan. Mahmoodi et al. (2013) [11] further applied the AHP model and GIS technology, and they adopted remote sensing technology to enrich the data source to build a human settlement evaluation system based on land livability. In addition, some scholars are keen on regional research. For example, Talen (2006) [12] took Chicago, the United States as a research object, and found that the diversity of society had promoted the rational allocation of resources through a discussion of the neighborhood level. However, most scholars have evaluated the human settlement with a focus at the regional level in selecting evaluation indicators, and it is difficult to reach an agreement because of the different research areas.

Human settlement is an emerging discipline category, and the influence of various constraints on the human settlement cannot be ignored. For example, Hruska (2006) [13] believed that there were certain laws among the many influencing factors of human settle- 
ment, and the relationship between the influencing factors should be studied. Subsequently, some scholars conducted research from the economic aspect. Arnstein (1969) [14] believed that better economic conditions imply more attention paid by local residents to the ecological environment, and the more people that appeal to the government, the more it is able to attract talents for ecological environment governance. Brown and Ulgiati (1997) [15] extended views to rural areas and believed that preventive taxes on rural ecological environment pollution should be levied. There are also scholars with an ecological point of view, such as Oke (1973) [16], who found that the change in human settlement was inseparable from the ecological environment factors, and the ecological environment played an important role in the change in human settlement. Gustafson et al. (2005) [17] used a linear regression model on this basis and explored the specific influence of natural factors on the human settlement. In addition, some scholars emphasize the role of humans in the human settlement. Aitken (1991) [18] believed that human behavior in the human settlement cannot be ignored, and that this is the key to solving the problem of improving the human settlement in the villages. Further, Clark et al. (2008) [19], based on Aitken's research and from the perspective of ecological city, regarded the harmonious coexistence of human and environment as the only way for the sustainable development of mountain cities. These scholars have conducted rich research on the constraints of the human settlement, however, they are mostly concentrated on the traditional ecological, economic, and humanities fields without considering financial support such as social capital investment and national fiscal expenditure factors.

Further exploring the relationship between financial support and the improvement of human settlements, the human settlements originally refers to the sum of everything that serves residents and uses residents' behavior as the carrier. In today's social development pattern, the human settlement environment is closely related to the concept of intelligent and sustainable development, and it mainly includes three aspects: ecological environment, infrastructure, and living conditions [20]. Because there are fewer studies directly related to financial support and human settlement, the academic community is inconsistent about the coupling effect of financial support and ecological environment, infrastructure, and living conditions. In terms of ecological environment, Gan and Bu (2020) [21] and Yao et al. (2014) [22], respectively, measured the coordination between the Yangtze River Basin and China's green finance and ecological environment, and found that the coupling and coordination between the two has been increasing year by year; Wu (2016) [23] constructed a spatial lag model, and he believed that financial agglomeration could significantly improve the regional ecological efficiency. Chen et al. (2017) [24] found that financial agglomeration positively affected the ecological efficiency of the eastern and western regions, however, its efficiency had a negative effect for the central zone. Furthermore, some scholars suggested that financial support has no obvious or even has a negative effect on the coupling effect of the ecological environment. For example, Selden and Holtz-Eakin (1995) [25] found that, before the economy has been developed to a certain higher level, the quality of the human settlement could not be given close attention. Pang et al. (2019) [5] asserted that the Yangtze River Economic Belt was generally lagging behind in financial agglomeration, lacking support for the ecological environment, and the economically underdeveloped areas were weaker than the economically developed areas. Yan et al. (2019) [26] considered that there is an imbalance between economy and ecology from the perspective of Australia. As far as infrastructure is concerned, Kim (1997) [27] perceived that financial support boosts infrastructure construction through the real estate industry. John and Anderson (2009) [28] also realized that finance exerts a supportive effect on real estate and infrastructure construction. In contrast, some scholars expressed objections, e.g., Jia et al. (2011) [29], who argued that rural financial development efficiency can result in a significant negative effect on rural infrastructure construction. Henderson and Wang (2006) [6] studied the impact of financial support on upgrading urban levels and found that investment in infrastructure had no effect on urbanization. Tomal (2020) [30] used Polish cities as a research object and found that nearly $90 \%$ of 
the studied cities have developed imbalances in their socio-economic and infrastructure development. In terms of living conditions, Leung et al. (2012) [31] reckoned that the rent subsidy policy produced a significant effect on improving family living conditions, however, Yu and Shen (2019) [32] believe that urban construction land that is against the direction of population agglomeration under financial incentives is more inclined to industrial use, which has a significant squeezing effect on the supply of residential land and the housing market. To sum up, scholars have accomplished great achievements in the research on the improvement effect of financial support to human settlement, however, investigation on the overall coupling effect of human settlement is rare.

In summary, academic research on the theory of human settlement and its derivatives is becoming more and more mature, however, the research on financial support and the improvement effect of human settlement remains difficult to unify. Some scholars, such as Leung et al. (2012) [31], hold an optimistic view of financial support in positively promoting the improvement of human settlement, while some scholars, such as Yu and Shen (2019) [32], noted that financial support had no obvious or even had some negative effect on the improvement of human settlement. Further, it can be seen from the above research that, first of all, the selection of human settlement indicators lacks commonality due to divergent research areas, and it is difficult to discover the general laws of human settlement development. Second, in the study of the constraints of human settlement environment, due to historical limitations, there is a shortage in discussions on financial support factors in modern society. Finally, while there are a number of studies on the role of financial support in the improvement of human settlement, there are only a few papers discussing the overall effect.

Therefore, this paper selects some common indicators of human settlement, and incorporates social idle funds into the financial support indicator system. In this paper, by investigating the coupling effect of financial support and human settlement improvement in the middle and lower regions of the Yangtze River, we aim to analyze the coupling mechanism, and summarize the spatiotemporal characteristics of coupling coordination between financial support and human settlement improvement. Meanwhile, this study serves to carry out an in-depth discussion on the coupling coordination evolution and regional heterogeneity, as well as to compare the research conclusion with the current mainstream views to explore whether the current financial support has a coupling effect on the human settlement. After the discussion above, this paper is expected to provide some ideas for the coordinated development of financial support and human settlement.

The content structure of the rest of the paper is as follows. Section 2 explains the research methods and data sources. Section 3 analyzes and discuss the results of the empirical process. Section 4 discusses the results of the empirical analysis. Section 5 clarifies the new findings in this paper, and then draws conclusions and enlightenment. Finally, shortcomings of this study and future prospect are provided.

\section{Material and Methods}

This chapter explains the data sources and the construction of the index system necessary for the empirical analysis of this article. In addition, the research method of this article and the division of coupling coordination types are clarified.

\subsection{Data Source}

The middle and lower regions of the Yangtze River traverse the two regions of central and eastern China, under the jurisdiction of Jiangsu, Shanghai, Zhejiang, Anhui, Jiangxi, Hubei, and Hunan (Figure 1). On the one hand, each province is located in the core area of the Yangtze River Economic Belt, and financial support policies vary greatly depending on the size of the economy. On the other hand, due to the limitations of history and natural conditions in the middle and lower reaches of the Yangtze River, the level of human settlements varies from province to province, with significant spatial differentiation. The middle and lower reaches of the Yangtze River have the typical characteristics of China's 
financial support and human settlements, which is representative for the study of the coordinated development of financial support and human settlements in China and even developing countries. Therefore, this article selects the middle and lower reaches of the Yangtze River as the research area. Financial support is an important way for the modern economy to carry out social construction [28], and it is also the main approach to improving the human settlement [4]. Therefore, the coupling research of financial support and human settlement improvement has become a problem that cannot be ignored at present.

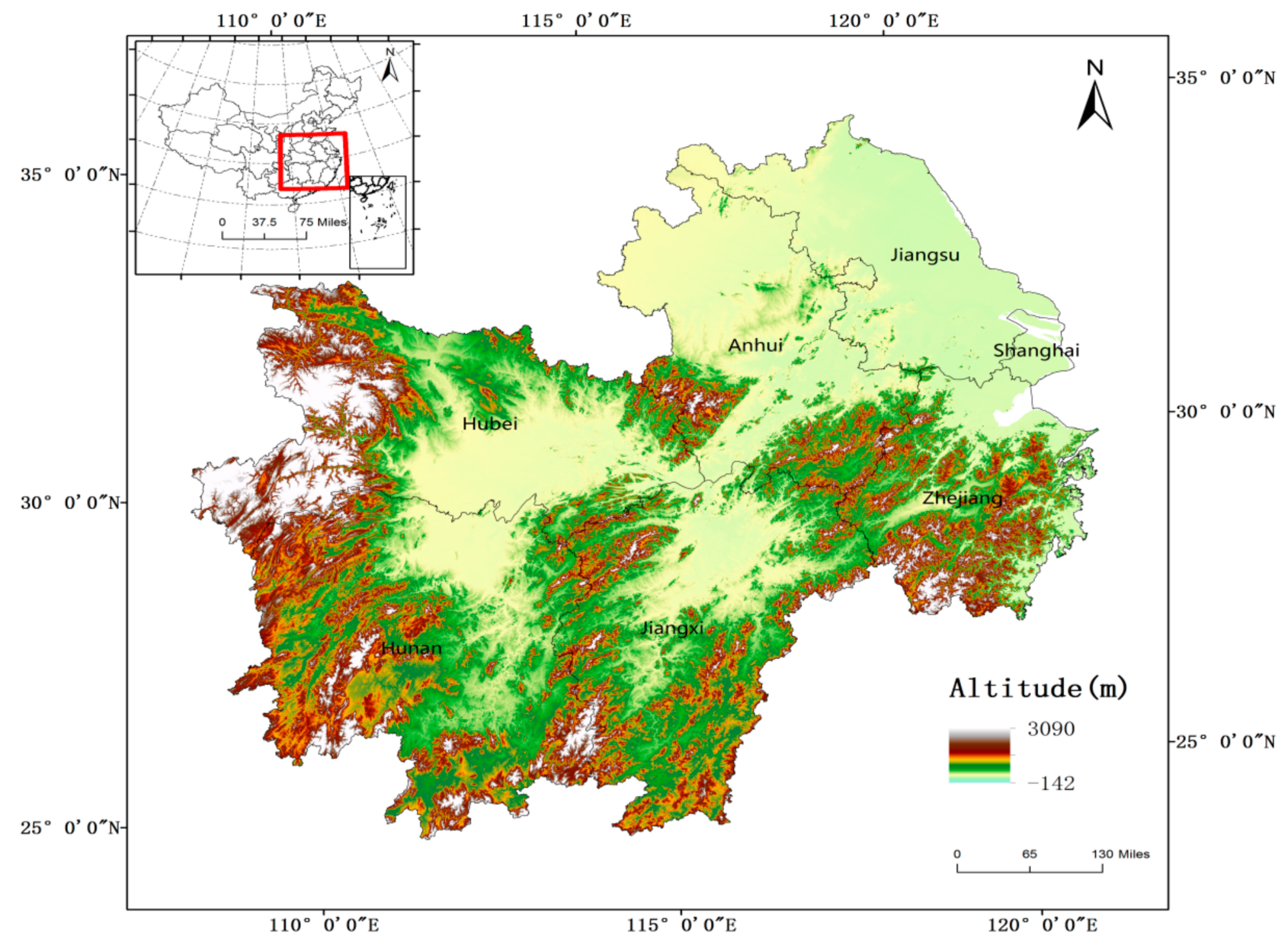

Figure 1. Location of middle and lower regions of the Yangtze River.

The data is selected from 'China Statistical Yearbook', 'China Environmental Yearbook', and provincial financial annual reports from 2005 to 2018, individual missing data are filled by linear regression interpolation. The two-dimensional vector boundary map of each province in the spatial autocorrelation analysis is derived from the map of each province after scanning.

\subsection{Indicators Selection}

Financial support indicators and human settlement indicators are a relatively complex setup system, including socioeconomic, ecological, and other factors. Adhering to the principles of availability, comprehensiveness, and scientificity of indicators, this paper selects two primary indicators of central and local general public budget expenditures and financial institution loans for the financial support system, a total of eight secondary indicators. Three first-level indicators of infrastructure, ecological environment, and living conditions are selected from the perspective of the human settlement, with a total of nine s-level indicators. The details are shown in Table 1. 
Table 1. Index system for financial support and improvement of human settlement.

\begin{tabular}{|c|c|c|c|c|}
\hline System Indicators & Primary Indicators & Secondary Indicators & Unit & Literature Basis \\
\hline \multirow{10}{*}{ financial support } & \multirow{6}{*}{ Fiscal expenditure } & Medical hygiene $\left(\mathrm{X}_{1}\right)$ & \multirow{10}{*}{100 million yuan } & Tang and Nie (2016) [33] \\
\hline & & Energy saving and & & \\
\hline & & environmental protection & & Zhi and Liang (2018) [34] \\
\hline & & expenditure $\left(X_{2}\right)$ & & \\
\hline & & $\begin{array}{c}\text { Urban and rural community } \\
\text { expenditure }\left(\mathrm{X}_{3}\right)\end{array}$ & & Qian et al. (2017) [35] \\
\hline & & House insurance $\left(\mathrm{X}_{4}\right)$ & & Qian et al. (2017) [35] \\
\hline & \multirow{4}{*}{ Financial institution loan } & $\begin{array}{c}\text { Water conservancy, } \\
\text { environment and public } \\
\text { facilities management }\left(X_{5}\right)\end{array}$ & & Zhang et al. (2011) [36] \\
\hline & & $\begin{array}{l}\text { Resident services, repairs and } \\
\text { other service industries }\left(X_{6}\right)\end{array}$ & & Zheng (2020) [37] \\
\hline & & Health and social work $\left(X_{7}\right)$ & & Qian et al. (2017) [35] \\
\hline & & Transportation and Post $\left(X_{8}\right)$ & & Zhang et al. (2011) [36] \\
\hline \multirow{9}{*}{$\begin{array}{l}\text { improvement of human } \\
\text { settlement }\end{array}$} & \multirow{4}{*}{ infrastructure } & $\begin{array}{l}\text { Hospital beds per } 1000 \text { people } \\
\qquad\left(\mathrm{Y}_{1}\right)\end{array}$ & \multirow{4}{*}{$\mathrm{m}^{2}$} & Zhu et al. (2010) [38] \\
\hline & & $\begin{array}{l}\text { Average number of students in } \\
\text { colleges and universities per } \\
100,000 \text { population }\left(\mathrm{Y}_{2}\right)\end{array}$ & & Wei et al. (2020) [39] \\
\hline & & Road area per capita $\left(\mathrm{Y}_{3}\right)$ & & Cui et al. (2019) [40] \\
\hline & & $\begin{array}{l}\text { Number of buses per } 10,000 \\
\text { people }\left(\mathrm{Y}_{4}\right)\end{array}$ & & Li et al. (2012) [41] \\
\hline & \multirow{2}{*}{ ecosystem } & $\begin{array}{l}\text { Public green area per capita } \\
\qquad\left(\mathrm{Y}_{5}\right)\end{array}$ & $\mathrm{m}^{2}$ & Wang et al. (2017) [42] \\
\hline & & $\begin{array}{l}\text { Harmless treatment rate of } \\
\text { municipal solid waste }\left(\mathrm{Y}_{6}\right)\end{array}$ & $\%$ & Peng et al. (2021) [43] \\
\hline & \multirow{3}{*}{ living conditions } & Water penetration rate $\left(\mathrm{Y}_{7}\right)$ & $\%$ & Zhu et al. (2010) [38] \\
\hline & & Gas penetration rate $\left(\mathrm{Y}_{8}\right)$ & $\%$ & Zhu et al. (2015) [44] \\
\hline & & $\begin{array}{l}\text { Domestic waste treatment rate } \\
\qquad\left(\mathrm{Y}_{9}\right)\end{array}$ & $\%$ & Peng et al. (2021) [43] \\
\hline
\end{tabular}

\subsection{Research Methods}

This paper adopts the system of 'financial support-improvement of human settlement' as the research object. According to the research ideas of Liu et al. (2017) [45], a comprehensive system coupling model consists of a coupling model, and a coupling coordination model is constructed. At the same time, a spatial autocorrelation model is developed to analyze the spatial clustering of the coupling coordination values.

\subsubsection{Entropy Method}

Because indicators about financial support and human settlement development differ in values, units, and professional fields, in order to eliminate the congenital defects of system indicators on the final result, the dimensionless processing is carried out on the index value first [46]. The range normalization is selected to process the index values, and the indicators are standardized as positive and negative indicators.

$$
\begin{aligned}
Z_{i j} & =\left\{X_{i j}-\operatorname{Min}\left(X_{j}\right)\right\} /\left\{\operatorname{Max}\left(X_{j}\right)-\operatorname{Min}\left(X_{j}\right)\right\}\left(\text { when } X_{i j} \text { is positive }\right) \\
Z_{i j} & =\left\{\operatorname{Max}\left(X_{j}\right)-X_{i j}\right\} /\left\{\operatorname{Max}\left(X_{j}\right)-\operatorname{Min}\left(X_{j}\right)\right\}\left(\text { when } X_{i j}\right. \text { is negative) }
\end{aligned}
$$

where $X_{i j}$ represents the value of the $i$-th indicator in year $j, \operatorname{Min}\left(X_{j}\right)$ and $\operatorname{Max}\left(X_{j}\right)$ denote the minimum and maximum values in the $j$-th year, and $Z_{i j}$ is the final standard value. In order to further eliminate the interference of human factors on the index value, the entropy method is applied in standardized index $Z_{i j}$ to obtain weight $W_{i j}$ [47].

In order to reduce the interference of subjective factors on the assignment of indicators, it is necessary to perform entropy processing on standardized indicators to obtain weights [47]. The specific methods are as follows: 
(1) Calculate entropy $e_{j}$

$$
e_{j}=(-1 / \ln m) \times \sum_{i=1}^{m}\left[\mathrm{x}_{i j} \times \ln x_{i j}\right]
$$

(2) Calculate the information entropy redundancy $g_{j}$, and the weight $w_{j}$

$$
g_{j}=1-e_{j} \quad w_{j}=g_{j} / \sum_{j=1}^{n} g_{i}
$$

(3) Index score

$$
U_{f}=\sum_{j=1}^{m} X_{i j} \times W_{i j} \quad U_{e}=\sum_{j=1}^{n} Y_{i j} \times W_{i j}
$$

where $U_{f}$ represents the Financial Support System Development Level Index, $m$ is the number of secondary indicators in the financial support system, $X_{i j}$ is the value of the $i$-th indicator in year $j, W_{i j}$ is the weight corresponding to $X_{i j}, U_{e}$ denotes the Habitat Environment System Development Index, $n$ is the number of secondary indicators in the human settlement system, $Y_{i j}$ is the value of the $i$-th indicator in year $j$, and $W_{i j}$ is the weight corresponding to $Y_{i j}$.

\subsubsection{Coupling Coordination Model}

$$
C=\left[\left(U_{f} \times U_{e}\right) /\left(U_{f}+U_{e}\right)^{2}\right]^{1 / 2} T=\partial \times U_{f}+\beta \times U_{e} \quad D=\sqrt{C \times T}
$$

where $C$ and $T$ are the coupling degree and comprehensive coordination index of financial support and human settlement environment system, respectively, and $\partial$ and $\beta$ are the undetermined coefficients for financial support and human settlement system, separately. In this study, they are both set to 0.5 [48], and $D$ is the comprehensive coordination for financial support and human settlement system.

\subsubsection{Spatial Autocorrelation Model}

The spatial autocorrelation method is a kind of exploratory spatial data analysis. It explores the interconnection and dependence between variables in the research object, including two theoretical models of global spatial autocorrelation and local spatial autocorrelation [45]. This study selects the coupling coordination as the object and, in the meantime, selects the Moran's I index, which is commonly used in index operations to study the spatial agglomeration characteristics among provinces and municipalities.

Global Moran's I:

$$
I_{g}=\left\{n \sum_{i=1}^{n} \sum_{j=1}^{n} W_{i j}\left(X_{i}-\bar{X}\right)\left(X_{j}-\bar{X}\right)\right\} /\left\{\left(\sum_{i=1}^{n} \sum_{j=1}^{n} W_{i j}\right) \sum_{i=1}^{n}\left(X_{i}-\bar{X}\right)^{2}\right\}
$$

Local Moran's I:

$$
I_{l}=\left\{n\left(X_{i}-\bar{X}\right) \sum_{i \neq j}^{n} W_{i j}\left(X_{j}-\bar{X}\right)\right\} /\left\{\sum_{i=1}^{n}\left(X_{i}-\bar{X}\right)^{2}\right\}
$$

where $I_{\mathrm{g}}$ denotes the global Moran Index, $I_{j}$ stands for the local Moran Index, $\mathrm{n}$ is the number of the samples, $X_{j}$ represents the coupling coordination value of the $i$-th State/Province, and $W_{i j}$ is the spatial weight, indicating the spatial relationship between the areas within 
the research object. Also, the adjacent space weight is used as the operation value: adjacent is recorded as 1 , and non-adjacent is recorded as 0 .

$$
Z=[I-E(I)] / \operatorname{VAR}(I)
$$

where $E(I)$ represents the expected value of the global Moran index, and $V A R(I)$ represents the standard deviation of the global Moran index.

\subsection{Coupling Characteristics Classification}

\subsubsection{Types of Coupling}

The degree of coupling refers to the degree of mutual influence and interaction between the financial support system and the human settlement system, ranging from 0 to 1 . This paper adopts the conclusions about the coupling degree achieved by Liu et al. (2017) [45], and takes the following divisions to the coupling degree (Table 2).

Table 2. Coupling types and content explanation for financial support and human settlement.

\begin{tabular}{ccc}
\hline & Type & Content \\
\hline $0.8<\mathrm{C} \leq 1$ & Superior coupling & Fully related and mostly based on positive promotion \\
$0.5<\mathrm{C} \leq 0.8$ & Benign coupling & Has entered a coupling process \\
$0.3<\mathrm{C} \leq 0.5$ & Moderate coupling & There is a trend of positive correlation, the interaction between the two is \\
$0 \leq \mathrm{C} \leq 0.3$ & Low coupling & The degree of association is not high, the overall chaos is disordered \\
\hline
\end{tabular}

\subsubsection{Types of Coupling and Coordination}

The degree of coordination refers to the study of the degree of coupling while also considering the degree of coordination between systems to explore the degree of coupling between financial support and human settlement system, which often ranges from 0 to 1 . This paper will be based on the results obtained by Gan and Bu (2020) [21], and takes the following divisions on the coordination level (Table 3).

Table 3. Financial support and human settlement coordination types.

\begin{tabular}{ccc}
\hline & Type & Content \\
\hline $0.7<\mathrm{D} \leq 1$ & Superior balanced development(I) & Enter the stage of coordinated development \\
$0.5<\mathrm{D} \leq 0.7$ & Barely balanced development(II) & Basic coordination, the overall coordination is optimized \\
$0.3<\mathrm{D} \leq 0.5$ & Slightly unbalanced development(III) & overall coordination is poor \\
$0<\mathrm{D} \leq 0.3$ & Seriously unbalanced development(IV) & Interaction is chaotic \\
\hline
\end{tabular}

\section{Result Analysis}

This paper first uses the coupling coordination model to measure the coupling value and coordination value of financial support and the improvement of the human settlements in the middle and lower reaches of the Yangtze River, and further studies the types of coupling and coordination and their spatial distribution. Secondly, the Moran index in spatial autocorrelation is used to study the spatial agglomeration characteristics of the coupling coordination value of financial support and the improvement of the human settlements.

\subsection{Analysis of Coupling Degree and Its Type Evolution Characteristics}

The overall coupling degree is fluctuating, however, the coupling degree of financial support and human settlement all changed within $0.3 \sim 0.5$ during the study period, and the overall coupling level was moderate. At the inter-provincial level, the numerical investigation of the coupling degree of each province from 2005 to 2018 (Figure 2) -despite the fact that individual provinces are in a low-level coupling stage in individual years, such as Zhejiang Province and Anhui Province in 2005-fluctuated and gradually increased to moderate. The coupling levels are close, similar to the overall situation in the research area. 


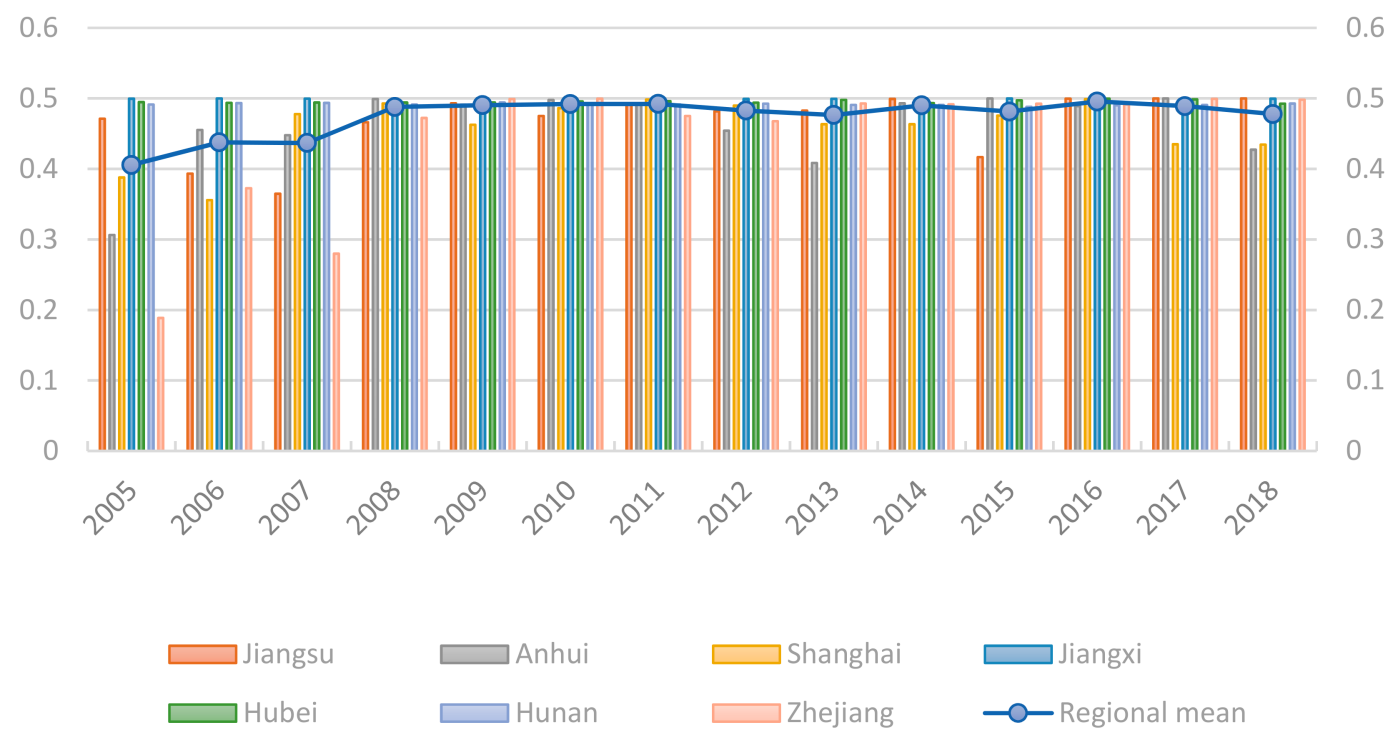

Figure 2. Evolution of coupling degree in 2005-2018.

\subsection{Analysis of Coordination Degree and Its Type Evolution Characteristics}

From the overall analysis of the research area (Figure 3), during the study period, the coordination between financial support and the improvement of the human settlement changed within 0.0338 0.4675. There are roughly two stages: (1) from 2005 to 2013, the degree of coordination between financial support and human settlement improvement system has increased year by year. The type of system coordination has gradually moved away from the seriously unbalanced development stage and developed towards the barely balanced development stage. The coordination relationship between the two has begun to develop optimally; (2) from 2013 to 2018, the system coordination value fluctuated, and the main coordination type is still dominated by the basic coordination phase. It is not difficult to see from the coordinated evolution curve of the financial support and human settlement improvement system the the coordinated development trend line of the system shows an inverted ' $U$ ' shape, which shows that the coordination index rises, while the development trend is unstable and has a downward trend.

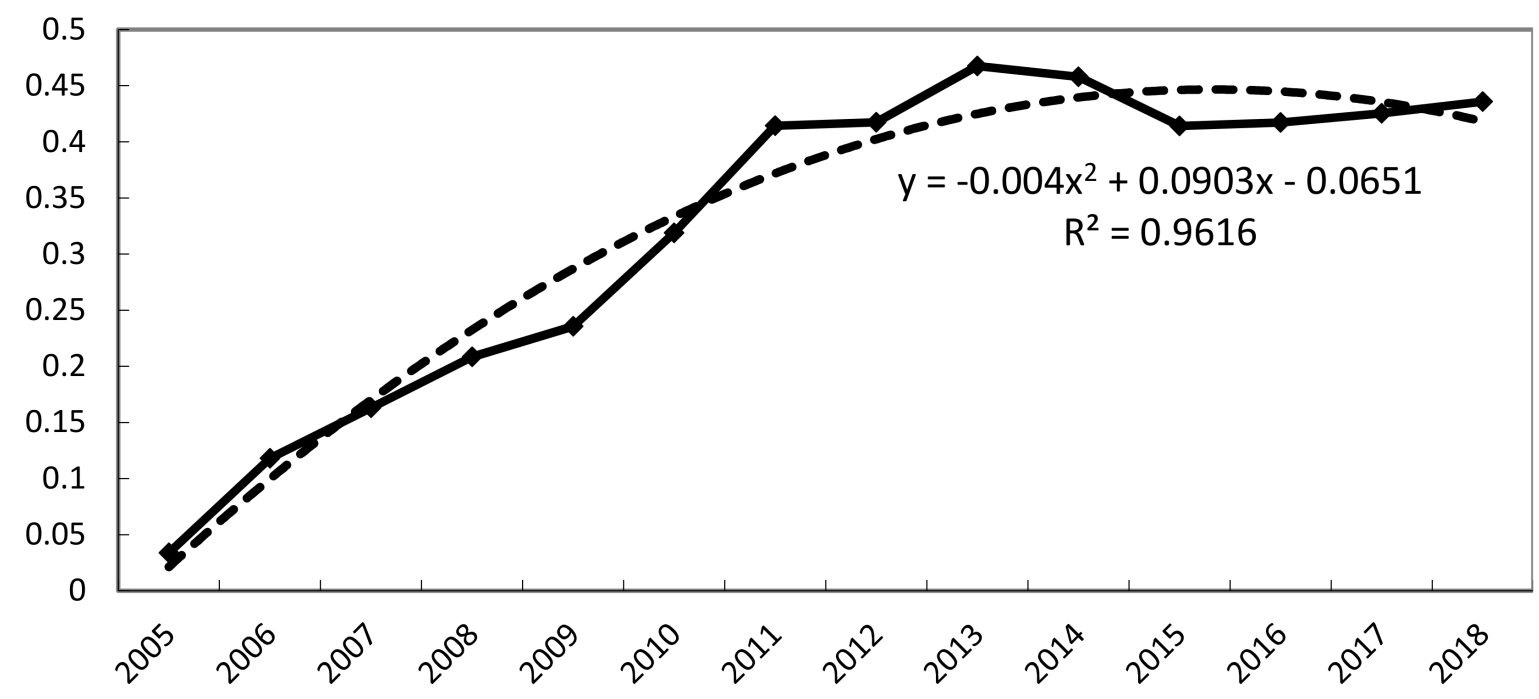

Figure 3. Evolution of coordination degree from 2005 to 2018. 
To further explore the evolution of provincial coupling types (Figure 4), there are three time periods during the study: (1) the number of coordination types during 2005-2013 was barely balanced development type $>$ slightly unbalanced development type $>$ superior balanced development type > seriously unbalanced development type; (2) in 2014-2017, the number of slightly unbalanced development type provinces decreased year by year, the barely balanced development type gradually became dominant, and the number of superior balanced development type provinces remained unchanged; (3) from 2017 to 2018, the number of barely balanced development type provinces declined slightly, however, it was still the dominant distribution.

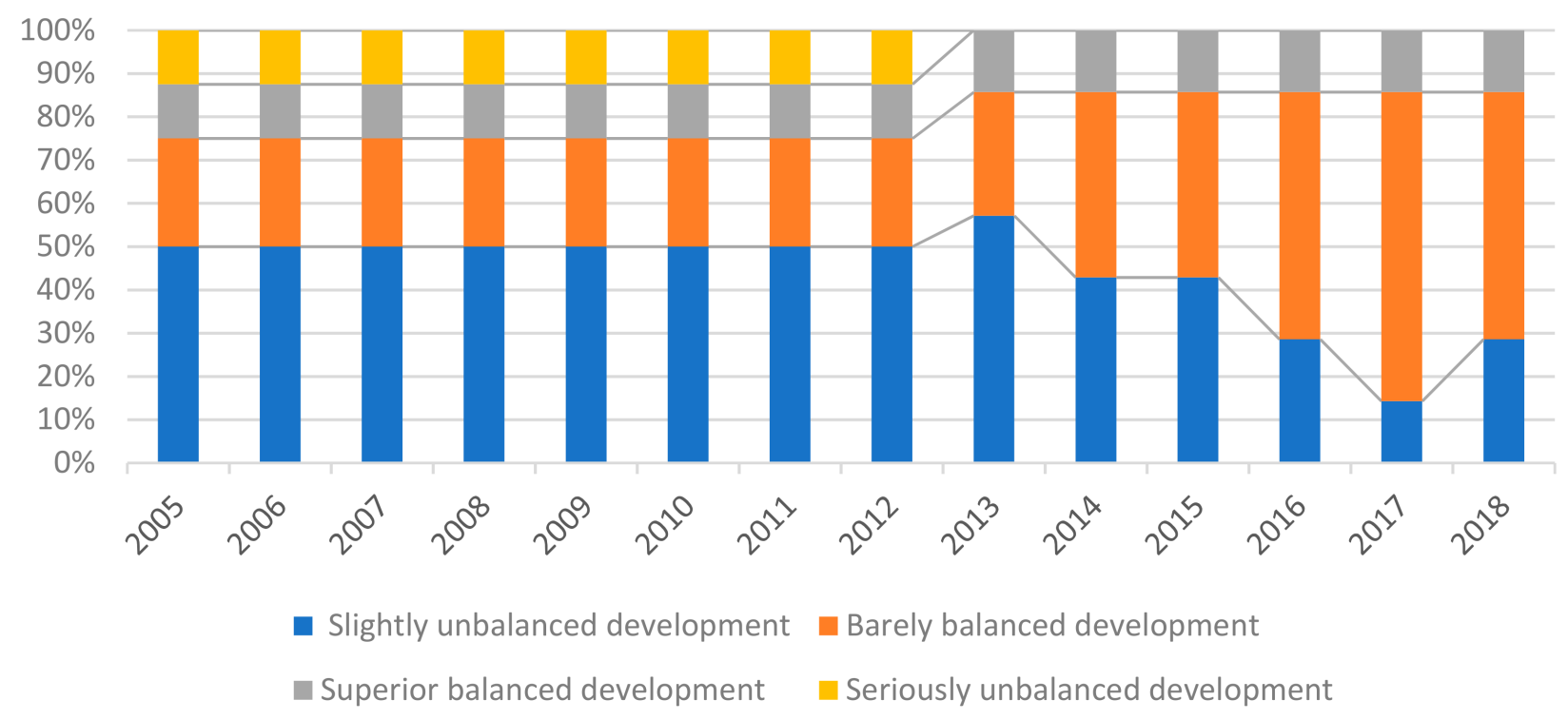

Figure 4. Evolution of coordination types from 2005 to 2018.

Combining coordination and synchronous development to study the type of coupling coordination, due to space reasons, this article selects four time nodes of 2005, 2009, 2014, and 2018 to explain. It can be seen from Figure 5 that the distribution of coupling coordination types shows significant regional heterogeneity. The coupling coordination types in the same areas, including Jiangxi, Hubei, and Hunan, are dominated by I and II, whose coupling effect is stronger than the eastern region. Among them, Hubei and Hunan are mainly type II, while Jiangxi has always been type I, which indicates the best type of coupling effect. The coupling and coordination types in the coastal area, represented by Shanghai, Jiangsu, Anhui, and Zhejiang, are mainly III and IV. Although the coupling and coordination development is not as good as that in the western region, the degree of coupling and coordination is deepening year by year. Taking Jiangsu as an example, the province has gradually grown from Type IV in 2005 to Type II in 2018, indicating that, although there are regional differences, the overall coupled and coordinated development is stable. 


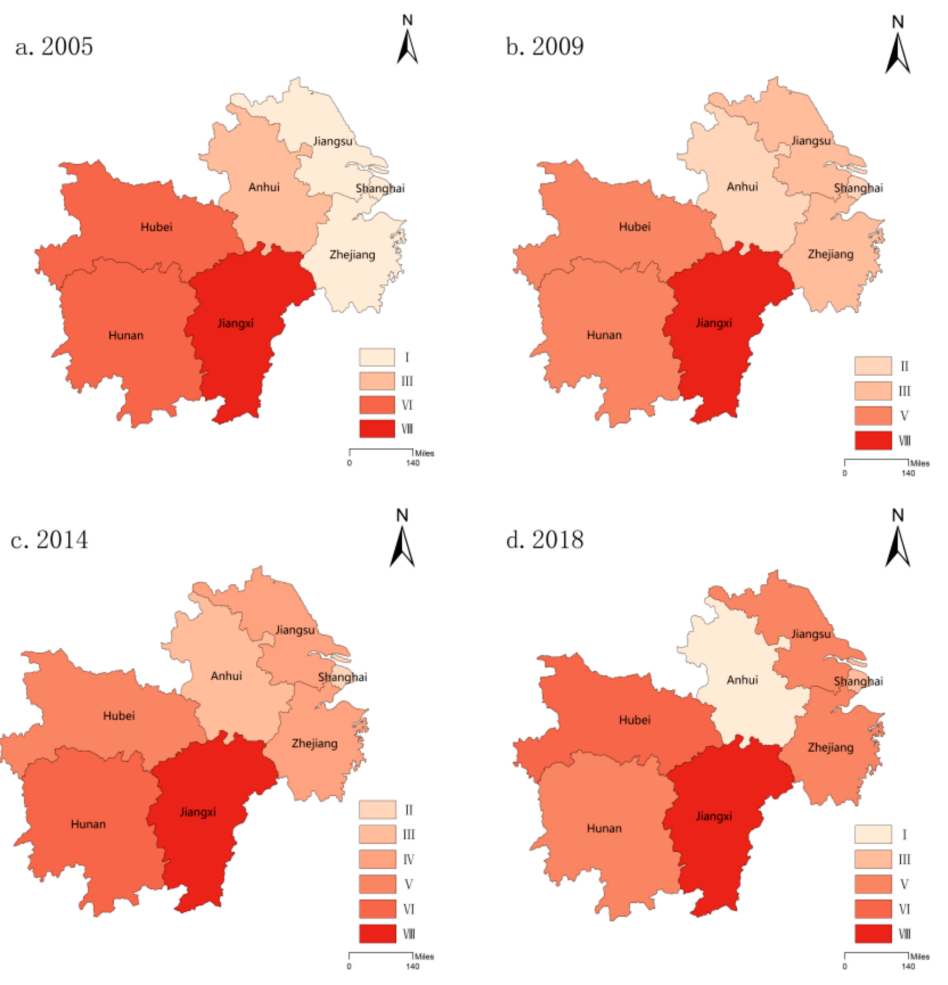

Figure 5. Types of coupling coordination in 2005 and 2018.

\subsection{Analysis of Provincial Spatial Autocorrelation and Its Type Evolution}

This paper takes the coupling coordination degree of financial support and the improvement of human settlement as the research variables, uses Geoda to calculate the Moran's I index of the coupling coordination degree over the years, and performs 9999 regressions to test the significance level. The results show that the $\mathrm{Z}$ value mostly passes the significance test of the confidence interval of 0.05 , and is significantly positive. The coupling coordination between financial support and human settlement has obvious spatial aggregation characteristics. The following data are a representative set of typical characteristic results (Table 4).

Table 4. Moran's I Index in 2005, 2009, 2014 and 2018.

\begin{tabular}{cccc}
\hline Year & Moran's I & E(I) & Z \\
\hline 2005 & 0.2515 & -0.1667 & 2.9363 \\
2009 & 0.2061 & -0.1667 & 2.0524 \\
2014 & 0.2090 & -0.1667 & 2.7159 \\
2018 & 0.2701 & -0.1667 & 3.3641 \\
\hline
\end{tabular}

Figure 6 shows the LISA agglomeration maps of 2005, 2009, 2014, and 2018 under the $5 \%$ significance level. The results show that: (1) the significant High-High type indicates that the spatial difference is not large, and the coupling coordination value between itself and the surrounding area is high, currently only in Jiangxi; (2) the significant Low-Low type presents a low-value agglomeration trend, and both itself and the surrounding areas are not high, mainly distributed in the coastal areas, such as Jiangsu in 2005 and 2009, and Shanghai in 2018; (3) significantly Low-High type reflects the characteristics of low selfcoupling coordination value, however, the characteristics of high coupling coordination value in surrounding areas, only in Hubei in 2005; (4) the significant High-Low type is opposite to the significant Low-High type, and the self-coupling coordination value is higher than that of the surrounding areas. It was distributed in Jiangsu in 2014 and 2018. 


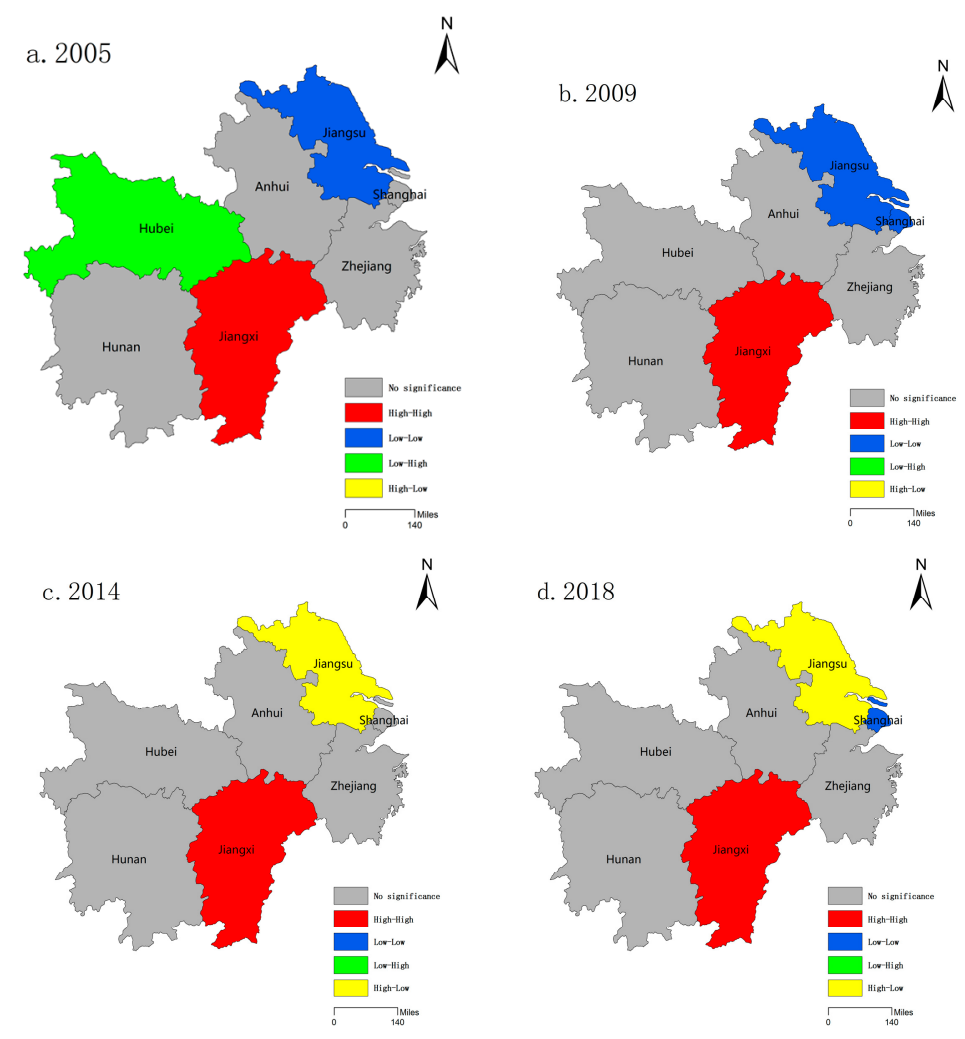

Figure 6. LISA Aggregation Map of Provincial Coupling Coordination. Note: The LISA (Local indicators of spatial association) cluster map reflects the local indicators of spatial association, reflecting the relationship between a region and its neighboring regions.

\section{Results Discussion}

Based on the empirical results in the middle and lower reaches of the Yangtze River in China, this article further discusses the empirical results to provide experience for developing countries to improve the level of human settlements, and ultimately guide the sustainable development of the environment in developing countries.

(1) The numerical values of the coupling degree indicate that the coupling characteristics of financial support and the improvement of the human settlement during the study period have evolved from a low degree of system correlation and overall chaos to an initial positive correlation trend in the system $[21,26]$. During the study period, the coordination degree value showed an inverted " $U$ " shape with a downward trend; however, Lu et al. (2017) [49] did not find a downward trend, which conflicted with the conclusion of this article. Probably because of the initial formation of the coupling system of financial support and human settlement, the provincial governments and financial institutions did not pay enough attention to the human settlement, and the financial support policies were chaotic, which results in that the initial financial support and the human settlement cannot form a good linkage relationship. However, since China officially put the human settlement on the agenda in 2007, the social human settlement awareness has been improved, the financial support policy has been gradually implemented as well as the degree of financial support, and the human settlement has slowly increased. Therefore, the improvement of the human settlement protection policy is inevitable. Although the degree of relevance has increased, the new energy industry needed to improve the living environment has begun to take shape, and the proportion of green and low-carbon companies is limited. This has hindered the progress of ecological maintenance and urbanization, and the coordination between financial support and the improvement of the human settlement system has a downward trend. It is recommended to further optimize the industrial layout and promote green finance; 
(2) During the study period, the evolution process of the coordination degree and coordination type was mainly running-in type, indicating that the financial support and the human settlement improvement system in the middle and lower reaches of the Yangtze River were basically coordinated [21,26,49], but still in a slightly unbalanced state [30]. In addition, there is obvious regional heterogeneity [50]. The coupling coordination type in the middle reaches of the Yangtze River is better than that in the lower reaches of the Yangtze River, which is contrary to the results of Pang et al. (2019) [5] and Yao et al. (2014) [22]. From a macro perspective, in recent years, the middle and lower regions of the Yangtze River have followed the development plan of the Yangtze River Basin. The flow of economic elements, resource elements, and talent elements has been frequent. The ecological environment along the river has been improved, and urbanization has been promoted in an orderly manner. The further improvement of the human settlement requires the state finance and local financial institutions to promote innovation-driven strategies, focusing on supporting strategic emerging industries such as new energy companies. The industrial structure is optimized while improving the human settlement. It is recommended to strengthen regional joint defense and joint control to unify the elements distribution;

(3) The above local LISA diagram shows that the spatial agglomeration characteristics of the middle and lower reaches of the Yangtze River also have significant regional heterogeneity [50], which contradicts the conclusions of scholars such as Yao et al. (2014) [22]. Among them, Jiangxi is in a significant High-High type, and the lower reaches of the Yangtze River, except for Jiangsu, which is in a significant High-Low type, are all in a low-value aggregation state. This is inseparable from China's multiple policy orientations. Specifically, Jiangxi has a large area and rich ecological resources. It is the best implementation area for the rising strategy and green development strategy of central China, which undoubtedly actively promotes the economic development of Jiangxi. This has laid the economic foundation for local governments and financial institutions to invest in green industries represented by the human settlements, and continuous financial support has promoted the conversion of local rich ecological resources into a higher level of human settlements. The continuous optimization of the human settlement environment also reflects the correctness of the strategy for the rise of the central region and the green development strategy, which further brings positive financial support. Jiangxi's conclusion reflects this external virtuous circle. In Jiangsu Province, as the entrance of Changiiang River, the development of rural and urban infrastructure, ecological resources, and living settlement conditions is fastened during the 'new normal'. Habitat environment and financial support agglomeration have obvious advantages over neighboring provinces and cities, and gradually exhibit an influence on the coastal area, which has become a radiation highland in the coastal area. There has formed a kind of coupling coordinate development spatial level which sets the axis of Jiangsu-Jiangxi, radiating coupling and coordinated development of the surrounding area. Therefore, it is recommended to highlight the dominant position of Jiangsu and Jiangxi and promote the financial support model.

In summary, both the coupled coordination model and the spatial autocorrelation analysis show that there is a significant coupling effect between financial support and the improvement of the human settlement environment in the middle and lower reaches of the Yangtze River, and prove that the coupling level is in the middle stage.

\section{Conclusions and Policy Implications}

Compared with the research of Pang et al. (2019) [5] and Lu et al. (2017) [49], this article is the first to quantify the coupling and coordination between financial support and the improvement of the human settlements in the middle and lower reaches of the Yangtze River in China from the two dimensions of time and space. This paper finds that financial support and the improvement of the human settlements also have a coupling effect as a whole, which confirms the viewpoint of Gan and Bu (2020) [21]. Therefore, this article believes that China's experience will have a positive impact on the development of human settlements in developing countries. Based on the results of the discussion part, the specific 
conclusions are as follows: (1) the coupling coordination value of financial support and improvement of human settlements fluctuated from 0.034 to 0.436 , showing an inverted U-shaped development trend as a whole. (2) The correlation between financial support and the improvement of the human settlements is currently in the stage of barely balanced development, and there is a gap between benign and coordinated development. (3) The coupling and coordination of financial support and human settlements have significant spatial agglomeration characteristics, and the coupling effect in the eastern region is weaker than that in the western region. In particular, Jiangxi was mainly distributed as HighHigh agglomeration, and Jiangsu was mainly distributed as High-Low agglomeration. A coupled and coordinated development area with Jiangsu-Jiangxi as the axis has been formed, radiating the development of adjacent areas.

Considering that China is the largest developing country, the experience from China's empirical research may provide guidance for developing countries to improve the level of human settlements. This article will provide policy recommendations from three aspects: the government, financial institutions, and enterprises. (1) The government should provide more policy support in the field of human settlements, such as advocating green financial policies, and increasing the state's fiscal expenditure on infrastructure and residents' welfare. At the same time, it should encourage green energy companies to participate in urban and rural community affairs, and guide social funds to flow to the field of human settlements. (2) Financial institutions should improve the green financial system, appropriately lower the financing threshold for green enterprises with development potential, and provide financial support for industrial upgrading and transformation to support the development of green industries. This is necessary to improve the human settlements. (3) Enterprises should strictly control the discharge of pollutants in the production process, and actively eliminate outdated production capacity. At the same time, they should improve the efficiency of resource utilization, increase the added value of products, and obtain sufficient credit support.

The financial support and human settlements system is very complicated. On the one hand, this article conducts a macro empirical study on the coupling and coordination of financial support and improvement of human settlements at the provincial level, and has not yet been refined to the city level; on the other hand, we will focus on possible changes in financial support policies in future research to extend the applicability of this research. Therefore, in the follow-up of this article, starting from the coastal city clusters, we will conduct an in-depth study of the coupling and coordination characteristics of the eastern coastal area to explore the problem of the unobvious coupling characteristics of the eastern area.

Author Contributions: W.Y., B.P., G.W. and A.W. made the equal contribution to the article. All authors have read and agreed to the published version of the manuscript.

Funding: This work was financially supported by Humanities and social sciences research project of the Ministry of Education (20YJAZH096), the Philosophy and Social Sciences bidding project of Wuxi (wxsk21-a-12), Jiangsu Province Soft Science Project (BR2021008).

Institutional Review Board Statement: Not applicable.

Informed Consent Statement: Not applicable.

Data Availability Statement: Not applicable.

Conflicts of Interest: All the authors declare that there is no conflict of interest.

\section{References}

1. Guan, J.; Kirikkaleli, D.; Bibi, A.; Zhang, W. Natural resources rents nexus with financial development in the presence of globalization: Is the "resource curse" exist or myth? Resour. Policy 2020, 66, 101641. [CrossRef]

2. Khan, M.A.; Ozturk, I. Examining foreign direct investment and environmental pollution linkage in Asia. Environ. Sci. Pollut. Res. 2019, 27, 7244-7255. [CrossRef] 
3. Dong, R.C.; Ouyang, Z.Y.; Shen, X.; Deng, H.B.; Zhao, J.Z. Problems and strategies for the establishment of integrated ecosystem management information system in the west of China. In Proceedings of the Third Ecological Summit, Beijing, China, 22-27 May 2007; pp. 70-71.

4. Qian, J.; Wang, G.; Ding, Y.; Liu, S. The land ecological evolutional patterns in the source areas of the Yangtze and Yellow Rivers in the past 15 years, China. Environ. Monit. Assess. 2006, 116, 137-156. [CrossRef]

5. Pang, Q.H.; Li, M.Z.; Li, H. Research on Spatial Coupling Coordinated Development Between Financial Agglomeration, Regional Innovation and Ecological Efficiency of Yangtze River Economic Belt. J. Ind. Technol. Econ. 2019, 38, 68-76.

6. Henderson, J.V.; Wang, H.G. Urbanization and city growth: The role of institutions. Reg. Sci. Urban Econ. 2007, 37, 283-313. [CrossRef]

7. Francescato, G. The Significance of Architectural Theory for Environmental Design. Res. Adv. Environ. Behav. Design 1991, 3, 3-52.

8. William, J.R. On the Rank-Size Distribution for Human Settlements. J. Reg. Sci. 2002, 42, 1-17.

9. Stidger, R.W. Rough roads in the city:How less-than-smooth surfaces affect traffic satefety and city liability. Better Roads 2003, 73, 30-36.

10. Ge, J.; Hokao, K. Residential environmental evaluation of local cities considering regional characteristic and personal residential preference-a case study of Saga City, Japan. J. Environ. Sci. 2004, 16, 138-144.

11. Mahmoodi, M.; Rafieian, M.; Shayan, S. Land Use Planning in the Urban Sensitive Areas Case Study, Farahzad Valley StreamTehran. Urban-Reg. Stud. Res. 2013, 16, 47-64.

12. Talen, E. Neighborhood-Level Social Diversity: Insights from Chicago. J. Am. Plan. Assoc. 2006, 72, 431-446. [CrossRef]

13. Hruska, K. Notes on the evolution and organization of the urban ecosystem. Urban Ecosyst. 2006, 9, 291-298. [CrossRef]

14. Arnstein, S.R. A Ladder of Citizen Participation. J. Am. Inst. Plan. 1969, 35, 216-224. [CrossRef]

15. Brown, M.; Ulgiati, S. Emergy-based indices and ratios to evaluate sustainability: Monitoring economies and technology toward environmentally sound innovation. Ecol. Eng. 1997, 9, 51-69. [CrossRef]

16. Oke, T.R. City size and the urban heat island. Atmos. Environ. 1973, 7, 769-779. [CrossRef]

17. Hammer, R.B.; Gustafson, E.J.; Radeloff, V.C.; Potts, R.S. The relationship between environmental amenities and changing human Settlement patterns between 1980 and 2000 in the Midwestern USA. Landsc. Ecol. 2005, 20, 773-789.

18. Aitken, S.C. Person-environment theories in contemporary perceptual and behavioural geography I: Personality, attitudinal and spatial choice theories. Prog. Hum. Geogr. 1991, 15, 179-193. [CrossRef]

19. Clark, J.K.; McChesney, R.; Munroe, D.K.; Irwi, E.G. Spatial characteristics of exurban settlement pattern in the United States. Landsc. Urban Plan. 2008, 90, 178-188. [CrossRef]

20. Chen, C.Y.; Zhang, W.Z.; Zhan, D.S.; Li, X.L. Quantitative evaluation of human settlement environment and influencing factors in the BohaiRim area. Progress in Geography. Prog. Geography. 2017, 36, 1562-1570.

21. Gan, Y.; Bu, Y. A Coordinated Assessment between Green Finance and Ecological Environment along the Yangtze River Basin. E3S Web Conf. 2020, 194, 05038. [CrossRef]

22. Yao, L.; Gu, G.F.; Lu, J.; Wang, J.K. Spatial pattern and regional disparity of regional economic integration and ecology environmental stress in China. World Reg. Stud. 2014, 23, 111-121.

23. Wu, J.F. Empirical Research on Spatial Measurement of Financial Agglomeration and Regional Ecological Efficiency. Stat. Decis. 2016, 3, 149-153.

24. Chen, L.X.; He, Y.Q.; Wang, Y.; Jia, W.Q. SD Simulation of the Spatial Panel Data of Financial Agglomeration, Economic Development and Eco-efficiency. Syst. Eng. 2017, 35, 23-31.

25. Holtz-Eakin, D.; Selden, T.M. Stoking the fires? $\mathrm{CO}_{2}$ emissions and economic growth. J. Public Econ. 1995, 57, 85-101. [CrossRef]

26. Yan, X.; Chen, M.; Chen, M.-Y. Coupling and Coordination Development of Australian Energy, Economy, and Ecological Environment Systems from 2007 to 2016. Sustainability 2019, 11, 6568. [CrossRef]

27. Kim, K.-H. Housing Finance and Urban Infrastructure Finance. Urban Stud. 1997, 34, 1597-1620. [CrossRef]

28. Anderson, J.E. Financing Urban Development in China. Chin. Econ. 2009, 42, 48-62. [CrossRef]

29. Jia, L.; Shi, Q.; Huang, X. An Analysis of the Support Effect of Rural Financial Development on Rural Infrastructure Construction. J. Agrotech. Econ. 2011, 11, 34-44.

30. Tomal, M. Analysing the coupling coordination degree of socio-economic-infrastructural development and its obstacles: The case study of Polish rural municipalities. Appl. Econ. Lett. 2020, 28, 1-6. [CrossRef]

31. Leung, C.K.Y.; Sarpca, S.; Yilmaz, K. Public housing units vs. housing vouchers: Accessibility, local public goods, and welfare. J. Hous. Econ. 2012, 21, 310-321. [CrossRef]

32. Yu, J.X.; Shen, K.R. The Impact of Urban Land Quota Allocation on China's Housing Market. Econ. Res. J. $2019,54,116-132$.

33. Tang, Q.M.; Nie, J. Coupled and Coordinated Development Evaluation of Health Investment and Health Benefits. Chin. Health Econ. 2016, 35, 68-70.

34. Zhi, I.; Liang, L.E.I. Environmental Effect of Local Government's Expenditure on Energy Saving\# br\# and Environmental Protection. J. Beijing Univ. Posts Telecommun. 2018, 20, 89.

35. Qian, C.; Hongru, W.; Zhiliang, N. Registration System Reform, Fiscal Expenditure Responsibility and Life Satisfaction of Rural Residents. Public Financ. Res. 2017, 4, 64-74.

36. Zhang, G.N.; Zhou, H.X.; Chen, G.H. The Optimal Infrastructure Investment Scale and Order: Some Empirical Evidence from Panel Data in China. Econ. Rev. 2011, 4, 23-30. 
37. Zheng, S. A Comparative Analysis of Wages Level of Private Enterprises in 30 Provincial Administrative Regions in China Based on Principal Component Analysis. In Proceedings of the Sixth International Forum on Decision Sciences; Springer: Singapore, 2019; pp. 79-87. [CrossRef]

38. Zhu, X.M.; Li, X.X.; Zhang, J. Coordinated Development of Human Settlement and Economy in County-level Cities in the Yellow River Basin. J. Landsc. Res. 2010, 2, 95-99. [CrossRef]

39. Wei, J.; Ding, Z.; Meng, Y.; Li, Q. Regional Sustainable Assessment at City Level Based on CSDIS (China Sustainable Development Indicator System) Concept in the New Era, China. Chin. Geogr. Sci. 2020, 30, 976-992. [CrossRef]

40. Cui, G.; Zhang, X.; Zhang, Z.; Cao, Y.; Liu, X. Comprehensive Land Carrying Capacities of the Cities in the Shandong Peninsula Blue Economic Zone and their Spatio-Temporal Variations. Sustainability 2019, 11, 439. [CrossRef]

41. Li, Y.; Zhou, Y.; Shi, Y.; Zhu, X. Investigation of a coupling model of coordination between urbanization and the environment. J. Environ. Manag. 2012, 98, 127-133. [CrossRef]

42. Wang, Y.; Jin, C.; Lu, M.; Lu, Y. Assessing the suitability of regional human settlements environment from a different preferences perspective: A case study of Zhejiang Province, China. Habitat Int. 2017, 70, 1-12. [CrossRef]

43. Peng, B.; Zhang, X.; Elahi, E.; Wan, A. Evolution of spatial-temporal characteristics and financial development as an influencing factor of green ecology. Environ. Dev. Sustain. 2021, 1-21. [CrossRef]

44. Zhu, B.; Zhang, X.L.; Yin, X. Evaluation of rural human settlements quality and its spatial pattern in Jiangsu Province. Econ. Geogr. 2015, 35, 138-144.

45. Liu, Y.; Pan, Y.C.; Tang, L.N. Spatiotemporal Coupling Characteristics of Agricultural Development and Farmers' Income at County-level in Beijing-Tianjin-Hebei Region. Econ. Geogr. 2017, 37, 141-147.

46. Wang, Y.; Peng, B.; Wei, G.; Elahi, E. Comprehensive Evaluation and Spatial Difference Analysis of Regional Ecological Carrying Capacity: A Case Study of the Yangtze River Urban Agglomeration. Int. J. Environ. Res. Public Health 2019, 16, 3499. [CrossRef]

47. Cao, Y.; Fan, X.; Guo, Y.; Li, S.; Huang, H. Multi-objective optimization of injection-molded plastic parts using entropy weight, random forest, and genetic algorithm methods. J. Polym. Eng. 2020, 40, 360-371. [CrossRef]

48. Ai, J.; Feng, L.; Dong, X.; Zhu, X.; Li, C. Exploring coupling coordination between urbanization and ecosystem quality (1985-2010): A case study from Lianyungang City, China. Front. Earth Sci. 2015, 10, 527-545. [CrossRef]

49. Lu, H.; Zhou, L.; Chen, Y.; An, Y.; Hou, C. Degree of coupling and coordination of eco-economic system and the influencing factors: A case study in Yanchi County, Ningxia Hui Autonomous Region, China. J. Arid. Land 2017, 9, 446-457. [CrossRef]

50. Zhao, Y.; Wang, S.; Ge, Y.; Liu, Q.; Liu, X. The spatial differentiation of the coupling relationship between urbanization and the eco-environment in countries globally: A comprehensive assessment. Ecol. Model. 2017, 360, 313-327. [CrossRef] 